\title{
The shape of the glucose concentration curve during an oral glucose tolerance test predicts risk for type 1 diabetes
}

\author{
Heba M. Ismail ${ }^{1} \cdot$ Ping Xu $^{2}$ • Ingrid M. Libman ${ }^{1}$ • Dorothy J. Becker ${ }^{1}$ • \\ Jennifer B. Marks ${ }^{3}$. Jay S. Skyler ${ }^{3}$. Jerry P. Palmer ${ }^{4}$ Jay M. Sosenko ${ }^{3}$. \\ Type 1 Diabetes TrialNet Study Group
}

Received: 21 February 2017 / Accepted: 15 August 2017 / Published online: 27 September 2017

(C) Springer-Verlag GmbH Germany 2017

\begin{abstract}
Aims/hypothesis We aimed to examine: (1) whether specific glucose-response curve shapes during OGTTs are predictive of type 1 diabetes development; and (2) the extent to which the glucose-response curve is influenced by insulin secretion. Methods Autoantibody-positive relatives of people with type 1 diabetes whose baseline OGTT met the definition of a monophasic or biphasic glucose-response curve were followed for the development of type 1 diabetes $(n=2627)$. A monophasic curve was defined as an increase in OGTT glucose between 30 and 90 min followed by a decline of $\geq 0.25 \mathrm{mmol} / \mathrm{l}$ between 90 and $120 \mathrm{~min}$. A biphasic response curve was defined as a decrease in glucose after an initial increase, followed by a second increase of $\geq 0.25 \mathrm{mmol} / \mathrm{l}$.
\end{abstract}

Members of the Type 1 Diabetes TrialNet Study Group are listed in the electronic supplementary material (ESM).

Electronic supplementary material The online version of this article (https://doi.org/10.1007/s00125-017-4453-6) contains peer-reviewed but unedited supplementary material, which is available to authorised users.

Heba M. Ismail

heba.ismail2@chp.edu

1 Division of Endocrinology, Diabetes and Metabolism, Children's Hospital of Pittsburgh of the University of Pittsburgh Medical Center, University of Pittsburgh, 4401 Penn Ave, FP 8129,

Pittsburgh, PA 15224, USA

2 Pediatrics Epidemiology Center, College of Medicine, University of South Florida, Tampa, FL, USA

3 Division of Endocrinology, Diabetes and Metabolism, Diabetes Research Institute, University of Miami Miller School of Medicine, Miami, FL, USA

4 VA Puget Sound Health Care System, Division of Endocrinology, Metabolism, and Nutrition, University of Washington, Seattle, WA, USA

Associations of type 1 diabetes risk with glucose curve shapes were examined using cumulative incidence curve comparisons and proportional hazards regression. C-peptide responses were compared with and without adjustments for potential confounders.

Results The majority of participants had a monophasic curve at baseline $(n=1732[66 \%]$ vs $n=895$ [34\%]). The biphasic group had a lower cumulative incidence of type 1 diabetes $(p<0.001)$, which persisted after adjustments for age, sex, BMI $z$ score and number of autoantibodies $(p<0.001)$. Among the monophasic group, the risk of type 1 diabetes was greater for those with a glucose peak at $90 \mathrm{~min}$ than for those with a peak at $30 \mathrm{~min}$; the difference persisted after adjustments $(p<0.001)$. Compared with the biphasic group, the monophasic group had a lower early C-peptide (30-0 min) response, a lower C-peptide index (30-0 min C-peptide/ $30-0 \mathrm{~min}$ glucose), as well as a greater $2 \mathrm{~h} \mathrm{C}$-peptide level $(p<0.001$ for all $)$.

Conclusions/interpretation Those with biphasic glucose curves have a lower risk of progression to type 1 diabetes than those with monophasic curves, and the risk among the monophasic group is increased when the glucose peak occurs at $90 \mathrm{~min}$ than at $30 \mathrm{~min}$. Differences in glucose curve shapes between the monophasic and biphasic groups appear to be related to C-peptide responses.

Keywords Glucose curve shape - Oral glucose tolerance test . Type 1 diabetes

\section{Abbreviations \\ Biphasic90}

Plasma glucose at $60 \mathrm{~min}$ dropped by $\geq 0.25 \mathrm{mmol} / 1$ after initial increase at $30 \mathrm{~min}$ and then increased again from the 60 to $90 \mathrm{~min}$ time points by $\geq 0.25 \mathrm{mmol} / \mathrm{l}$ 
Biphasic120 Plasma glucose at 60 min dropped by $\geq 0.25 \mathrm{mmol} / \mathrm{l}$ after initial increase at $30 \mathrm{~min}$ and then increased again from the 90 to 120 min time points by $\geq 0.25 \mathrm{mmol} / 1$

Monophasic30 Plasma glucose increased after an oral glucose load to the maximum at $30 \mathrm{~min}$, then decreased until $120 \mathrm{~min}$, with a final decline of $\geq 0.25 \mathrm{mmol} / 1$ between 90 and $120 \mathrm{~min}$.

Monophasic60 Plasma glucose increased after an oral glucose load to the maximum at $60 \mathrm{~min}$, then decreased until $120 \mathrm{~min}$, with a final decline of $\geq 0.25 \mathrm{mmol} / \mathrm{l}$ between 90 and $120 \mathrm{~min}$.

Monophasic90 Plasma glucose increased after an oral glucose load to the maximum at $90 \mathrm{~min}$, then decreased until $120 \mathrm{~min}$, with a final decline of $\geq 0.25 \mathrm{mmol} / \mathrm{l}$ between 90 and $120 \mathrm{~min}$. TrialNet Pathway to Prevention

\section{Introduction}

The $2 \mathrm{~h}$ OGTT is traditionally used for the diagnosis of diabetes, as well as for classifying glucose tolerance status as normal or impaired [1]. However, little attention is paid to the glucose changes at different time points or the morphology of the glucose curve during the $2 \mathrm{~h}$ interval. Most non-diabetic individuals demonstrate a monophasic 2 h OGTT pattern in which there is an initial increase in glucose that peaks at 30 or $60 \mathrm{~min}$, followed by a decline without a secondary increase [2-4]. Although a secondary increase (or biphasic pattern) occurring in a minority of people has long been observed, its implications are still not fully understood.

The relationship between the shape of the glucose-response curve during an OGTT and risk for type 2 diabetes development has been well studied in both adolescents and adults [5-12]. Specifically, those with a monophasic response curve were shown to have more evidence of metabolic abnormalities as well as a higher risk for the development of type 2 diabetes compared with those with a biphasic response curve.

The relevance of the shape of the glucose-response curve during a $2 \mathrm{~h}$ OGTT to the development of type 1 diabetes has not yet been studied. Moreover, the role of insulin secretory patterns in generating the various glucose shapes of OGTTs is not well understood. Thus, we have assessed whether specific shapes of glucose-response curves during $2 \mathrm{~h}$ OGTTs are predictive of the development of type 1 diabetes in autoantibodypositive relatives of individuals with type 1 diabetes. In addition, we examined the relation of the glucose-response curve to C-peptide secretory patterns.

\section{Methods}

Participants Data from autoantibody-positive (for at least one autoantibody type: GAD autoantibodies [GADA], insulinoma-associated-2 autoantibodies [IA-2A], micro insulin autoantibodies [mIAA] and/or islet cell autoantibodies [ICA]) relatives of people with type 1 diabetes were analysed. Those relatives were followed in the TrialNet Pathway to Prevention (PTP) study for the development of type 1 diabetes. The PTP study is a longitudinal observational study that has been previously described [13]. Out of a total of 3842 participants, 278 with diabetic OGTTs at baseline were excluded from the analyses. Further, those whose glucose curve did not meet the definitions of a monophasic or biphasic glucose curve $(n=937)$ were excluded from the analyses. OGTT data from the remaining 2627 participants were analysed. Institutional review board approval of the study was obtained at all participating sites, and written informed consent and assent, as applicable, were obtained.

Procedures OGTTs were performed at baseline and at all follow-up visits. For participants entered into the PTP before 2012, the interval between visits has been every 6 months. However, since 2012, those entered into the PTP have been followed either every 6 months or annually, depending on the degree of risk [14]. Following a $10 \mathrm{~h}$ overnight fast, fasting levels for glucose and C-peptide were obtained. Participants then ingested a $1.75 \mathrm{~g} / \mathrm{kg}$ oral glucose load (maximum $75 \mathrm{~g}$ ). Venous blood samples were obtained at $30 \mathrm{~min}$ intervals after the glucose load for up to $2 \mathrm{~h}$ for determination of both plasma glucose and C-peptide levels.

A fasting glucose level of $\geq 7.00 \mathrm{mmol} / \mathrm{l}$ and/or a $2 \mathrm{~h}$ glucose level of $\geq 11.01 \mathrm{mmol} / \mathrm{l}$ prompted a repeat OGTT for confirmation. If, on repeat testing, either the fasting or the $2 \mathrm{~h}$ glucose threshold was exceeded again, type 1 diabetes was diagnosed. Those who did not exceed either threshold on the confirmatory OGTT continued to be followed with serial OGTTs. The time of diagnosis was assigned to the date of the second confirmatory OGTT. A diagnosis could also be made without an OGTT, based on the clinical presentation. Glucose was measured by the glucose oxidase method and Cpeptide was measured by a two-site immunoenzymometric assay performed on a Tosoh 600 II analyser (Tosoh Bioscience, South San Francisco, CA, USA). The upper limit for the C-peptide assay is $9.99 \mathrm{nmol} / \mathrm{l}$ and the lower limit as low as $0.007 \mathrm{nmol} / 1$ with inter- and intra-assay coefficients of variation $<10 \%$.

Classification of the glucose-response curve Definitions for 'phasic' glucose-response curves were similar to those previously described by Tschritter et al [5]. Specifically, the glucose curve shape was classified as 'monophasic' when plasma glucose increased after an oral glucose load to the maximum at 
30,60 or $90 \mathrm{~min}$ and then decreased until $120 \mathrm{~min}$, with a final decline of $\geq 0.25 \mathrm{mmol} / \mathrm{l}$ between 90 and $120 \mathrm{~min}$. Those with glucose curves that decreased after an initial increase and then increased again by $\geq 0.25 \mathrm{mmol} / 1$ at any time were classified as 'biphasic'. We used a more specific criterion, a glucose increase of $\geq 0.25 \mathrm{mmol} / 1$ occurring at $30 \mathrm{~min}$, than Tschritter et al for the initial glucose rise. Based on the glucose assay used in the PTP study (mean intra- and inter-assay coefficients of variation both $<2 \%$ ), there is $95 \%$ confidence that a glucose change $\geq 0.25 \mathrm{mmol} / 1$ is not due to assay variation.

We further classified the biphasic group into two subgroups, based on timing of the second glucose peak after the initial drop: (1) biphasic90, if the plasma glucose at $60 \mathrm{~min}$ dropped by $\geq 0.25 \mathrm{mmol} / 1$ after the initial increase at $30 \mathrm{~min}$ and then increased again from the 60 to $90 \mathrm{~min}$ time points by $\geq 0.25 \mathrm{mmol} / \mathrm{l}$; and (2) biphasic 120 , if the plasma glucose at $60 \mathrm{~min}$ dropped by $\geq 0.25 \mathrm{mmol} / \mathrm{l}$ after the initial increase at $30 \mathrm{~min}$ and then increased again from the 90 to $120 \mathrm{~min}$ time points by $\geq 0.25 \mathrm{mmol} / 1$.

The monophasic curves were also further classified according to the timing of the peak glucose response between 30 and $90 \mathrm{~min}$. The three monophasic subgroups were designated as: (1) monophasic30, with peak glucose at $30 \mathrm{~min}$; (2) monophasic60, with peak glucose at $60 \mathrm{~min}$; and (3) monophasic90, with peak glucose at $90 \mathrm{~min}$. These definitions are consistent with those used by Kanauchi et al [6] for monophasic subgroups.

Measures of beta cell function C-peptide levels at all OGTT time points $(0,30,60,90$ and $120 \mathrm{~min})$ and AUCs for Cpeptide levels were studied to examine the possible contribution of insulin secretion to the glucose curve shape. In addition, we assessed the early (30-0 $\mathrm{min}$ ) C-peptide response, which has been shown to correlate well with the first-phase insulin response derived from IVGTTs $(r=0.50, p<0.001)$ $[15,16]$.

To further analyse the effect of C-peptide changes on glucose curve shape, the C-peptide index (30-0 min C-peptide/ 30-0 min glucose) and the AUC C-peptide/AUC glucose were evaluated. The C-peptide index and the AUC C-peptide/AUC glucose are OGTT-derived indices of beta cell function that have been previously described and validated [17].

Statistical analyses Unpaired Student's $t$, Pearson $\chi^{2}$ and Kruskal-Wallis tests were used for comparisons. Logrank tests were used to compare cumulative incidence curves for progression to type 1 diabetes. Univariate and multivariate proportional hazards regression models were used to examine type 1 diabetes associations. Adjustments were made for age, sex, BMI $z$ score and autoantibody status (single vs two or more autoantibodies) at baseline. Nonnormally distributed values were $\log$ transformed. A twosided $p$ value $<0.05$ was used for statistical significance.
Statistical analyses were performed with SAS (version 9.4; SAS Institute, Cary, NC, USA).

\section{Results}

Baseline characteristics More PTP participants had a monophasic than a biphasic glucose-response curve at baseline ( $n=1732$ [66\%] vs $n=895$ [34\%], respectively). Table 1 summarises the baseline characteristics of participants grouped according to the overall shape of the glucoseresponse curve. Participants with a biphasic response were younger $(p<0.001)$ and had a lower proportion of two or more autoantibodies $(p<0.001)$ than those with a monophasic response.

Among the biphasic subgroups, the biphasic90 group were significantly younger $(p=0.026)$ with a higher median BMI $z$ score $(p=0.007)$ than the biphasic120 group (electronic supplementary material [ESM] Table 1). Among the monophasic subgroups, those with a peak glucose at $90 \mathrm{~min}$ had a higher BMI $z$ score $(p=0.003)$ and a greater proportion with two or more autoantibodies $(p=0.002)$ than those with a peak at 30 min (ESM Table 2).

Risk according to baseline glucose-response curve In the monophasic group, $21 \%$ developed type 1 diabetes $(n=365 /$ 1732), compared with $9 \%$ in the biphasic group $(n=81 / 895)$ during follow-up. Figure 1 shows the cumulative incidence curves for type 1 diabetes for the monophasic and biphasic groups. The cumulative incidence for type 1 diabetes was significantly lower for the biphasic group $(p<0.001)$ than for the monophasic group ( 5 year estimates: 0.18 for biphasic group vs 0.35 for monophasic group). The HR from a proportional hazards regression model (with $95 \%$ CIs) reflects the lower risk of the biphasic group $(\mathrm{HR}=0.40[0.31,0.51]$; $p<0.001)$. After adjusting for age, sex, BMI $z$ score and number of autoantibodies, the association persisted $(\mathrm{HR}=0.43[0.34,0.55] ; p<0.001)$.

In the biphasic90 group, $12 \%$ developed type 1 diabetes ( $n=43 / 346$ ) compared with $7 \%$ in the biphasic120 group ( $n=38 / 549$ ) during follow-up. The cumulative incidence was significantly higher $(p=0.014)$ in the biphasic90 group than in the biphasic120 group (5 year risk estimates: 0.24 vs 0.13) (ESM Fig. 1). However, in a proportional hazards regression model, there was no longer significance after adjusting for age, sex, BMI $z$ score and number of autoantibodies $(\mathrm{HR}=0.84[0.54,1.30] ; p=0.422)$.

Among the monophasic subgroups, $13 \%$ developed type 1 diabetes in the monophasic30 group $(n=76 / 565)$ vs $23 \%$ in the monophasic60 group $(n=199 / 880)$ and $31 \%$ in the monophasic90 group (90/287) during follow-up. The cumulative incidence for type 1 diabetes development (Fig. 2) was lower $(p<0.001)$ for those in the monophasic30 group compared with 
Table 1 Demographic characteristics of participants classified according to the shape of the baseline OGTT glucose curve

\begin{tabular}{llll}
\hline Characteristic & Monophasic $(n=1732)$ & Biphasic $(n=895)$ & $p$ value $^{\mathrm{a}}$ \\
\hline Median age, years (IQR) & $13.00(7.78-28.87)$ & $11.54(7.80-17.78)$ & $<0.001$ \\
Aged $\geq 18$ years, \% & 34 & 24 & $<0.001$ \\
Male, \% & 48 & 50 & 0.444 \\
Median BMI $z$ score (IQR) & $0.50(-0.26-1.27)$ & $0.50(-0.22-1.22)$ & 0.495 \\
Median time to type 1 diabetes or & $1.70(0.60-3.70)$ & $2.03(0.60-3.83)$ & 0.193 \\
$\quad$ last follow-up in years (IQR) & 68 & 55 & $<0.001$ \\
Two or more antibodies, \% & & 55 & \\
\hline
\end{tabular}

${ }^{\text {a }}$ Kruskal-Wallis test was used to compare the medians between groups; Pearson $\chi^{2}$ test was used to compare the proportions between groups

IQR, interquartile range those in either the monophasic 60 or the monophasic90 groups ( 5 year estimates: 0.26 vs 0.37 vs 0.46 , respectively). Compared with the monophasic30 group, the monophasic90 group had a higher risk of developing type 1 diabetes $(\mathrm{HR}=1.87$ [1.37, 2.57]; $p<0.001$ ) after adjusting for age, sex, BMI $z$ score and number of autoantibodies at baseline. Similarly, after adjustments were made, the monophasic 60 group had a higher risk of developing type 1 diabetes than the monophasic30 group $(\mathrm{HR}=1.57[1.20$, 2.06]; $p=0.001$ ).

Glucose and C-peptide responses in the monophasic and biphasic groups Glucose levels for the monophasic and biphasic groups according to OGTT time points are presented in Fig. 3a. The monophasic group had significantly higher glucose levels at 30,60, 90 and 120 min compared with the biphasic group ( $p<0.001$ for all). After adjusting for differences in age, sex, BMI $z$ score and number of autoantibodies, these differences remained significant $(p<0.001$ for all).

C-peptide levels (Fig. 3b) were higher in the biphasic group at $30 \mathrm{~min}(p<0.001)$, and lower at 60,90 and $120 \mathrm{~min}$
( $p<0.001$ for all). The early C-peptide response, the Cpeptide index and the AUC C-peptide/AUC glucose were all higher in the biphasic group ( $p<0.001$ for all) (Table 2). After adjusting for age, sex, BMI $z$ score and number of autoantibodies, the differences persisted $(p<0.001)$.

Glucose and C-peptide responses in the biphasic subgroups We compared glucose and $\mathrm{C}$-peptide changes during the OGTTs between the two biphasic subgroups (Fig. 3c, d). There were substantial differences between the groups. Cpeptide levels continued to decline between 30 and $60 \mathrm{~min}$ in the biphasic90 group, whereas C-peptide levels increased in the biphasic120 group. Moreover, changes were in opposite directions between the groups for both glucose and C-peptide after $60 \mathrm{~min}$. As is evident in Fig. 3d, the C-peptide response also manifested a biphasic pattern in both groups.

The early C-peptide response, the C-peptide index and the AUC C-peptide/AUC glucose were similar between the groups. Whereas the mean AUC glucose was higher in the biphasic90 group, the mean $2 \mathrm{~h}$ C-peptide was
Fig. 1 A comparison of cumulative incidence curves (with 95\% CIs) for type 1 diabetes between the monophasic (continuous line) and biphasic (dashed line) groups, $p<0.001$. T1D, type 1 diabetes

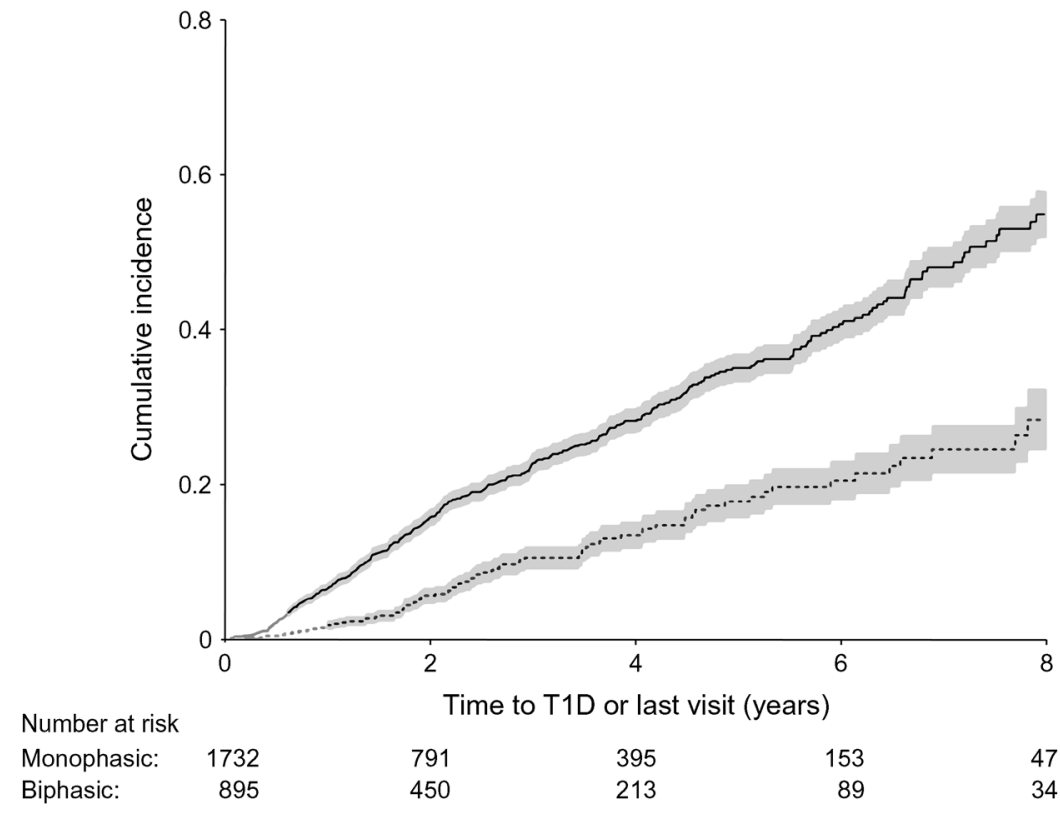


Fig. 2 Comparisons of the cumulative incidence curves (with 95\% CIs) for type 1 diabetes in the monophasic30, the monophasic60 and the monophasic90 groups; $p<0.001$ for monophasic30 vs monophasic60 and $p<0.001$ for monophasic30 vs monophasic90. Solid line, monophasic30; dashed line, monophasic60; dotted line, monophasic90. T1D, type 1 diabetes

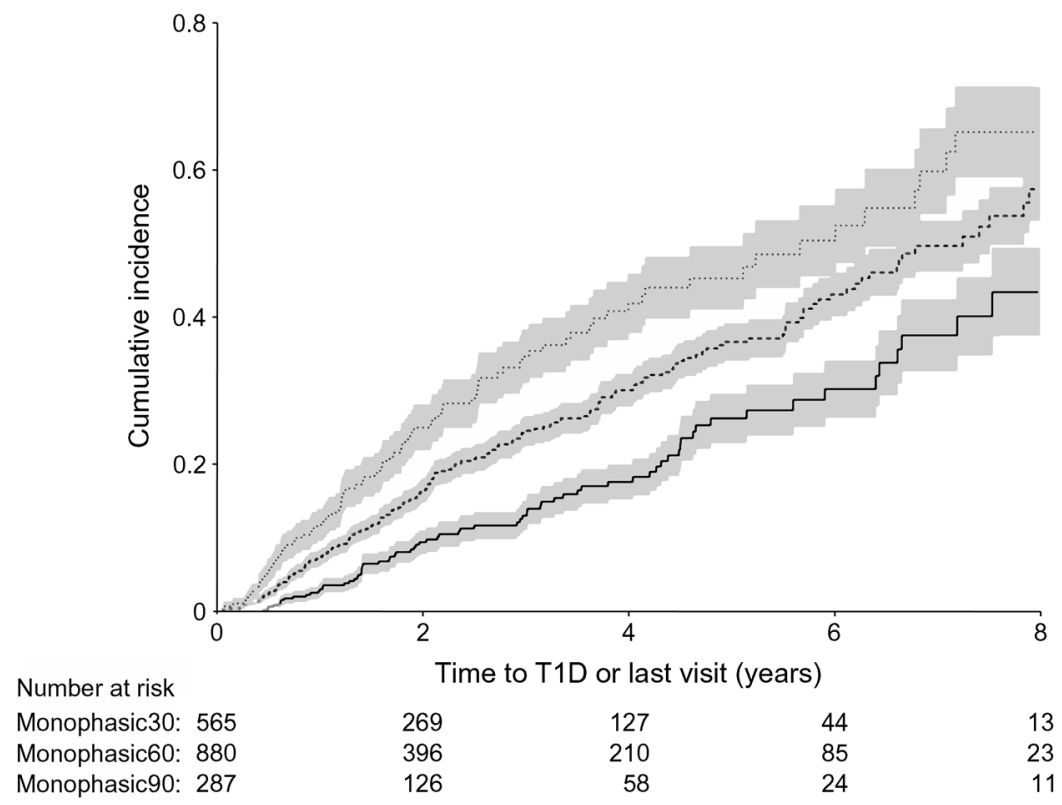

higher in the biphasic120 group ( $p<0.001$ and $p=0.001$, respectively) (Table 3 ).

$\mathrm{C}$-peptide responses in the monophasic subgroups The AUC C-peptide, early C-peptide response, C-peptide index
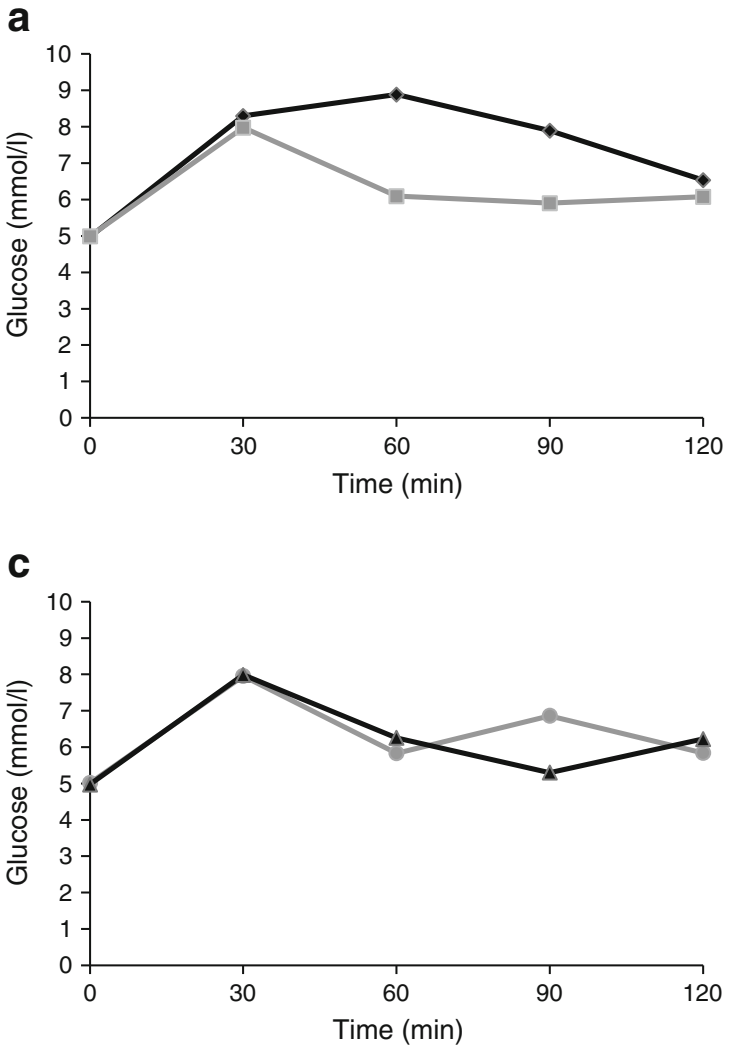

Fig. 3 Mean response curves for glucose (a, c) and C-peptide (b, d) during $2 \mathrm{~h}$ OGTTs. (a, b) Monophasic group compared with the biphasic group $(p<0.001$ for differences in both glucose and C-peptide levels at 30, 60, 90 and $120 \mathrm{~min}$ ). (c, d) Biphasic90 compared with biphasic120 and AUC C-peptide/AUC glucose ratios were all higher in the monophasic30 subgroup compared with the monophasic90 subgroup ( $p<0.001$ for all). In contrast, the mean $2 \mathrm{~h}$ C-peptide response was higher in the monophasic90 subgroup than in the monophasic30 subgroup $(p<0.001)$. All
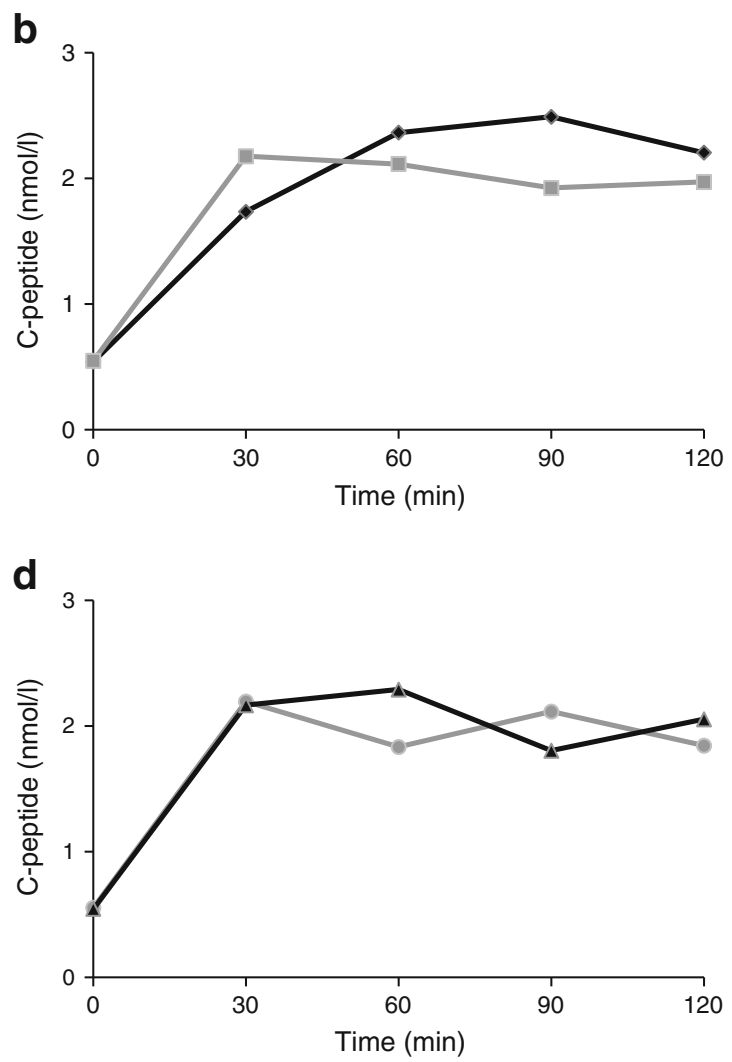

( $p<0.001$ for differences in both glucose and C-peptide levels at 60, 90 and $120 \mathrm{~min}$ ). Black diamonds, monophasic; grey squares, biphasic; grey circles, biphasic90; black triangles, biphasic120 
Table 2 Metabolic characteristics of participants according to the baseline OGTT glucose curve shape

\begin{tabular}{|c|c|c|c|c|}
\hline Characteristic & $\begin{array}{l}\text { Monophasic } \\
(n=1732)\end{array}$ & $\begin{array}{l}\text { Biphasic } \\
(n=895)\end{array}$ & $p$ value $^{\mathrm{a}}$ & $\begin{array}{l}\text { Adjusted } \\
p \text { value }^{\mathrm{b}}\end{array}$ \\
\hline AUC glucose, $\mathrm{mmol} / \mathrm{l}^{\mathrm{c}}$ & $7.84 \pm 1.36$ & $6.56 \pm 1.06$ & $<0.001$ & $<0.001$ \\
\hline AUC C-peptide, nmol// $1^{\mathrm{c}}$ & $2.03 \pm 0.99$ & $1.93 \pm 0.81$ & 0.002 & 0.072 \\
\hline 2 h C-peptide, nmol/1 & $2.21 \pm 1.18$ & $1.97 \pm 0.96$ & $<0.001$ & $<0.001$ \\
\hline Early C-peptide response, nmol/1 & $1.19 \pm 0.76$ & $1.63 \pm 0.82$ & $<0.001$ & $<0.001$ \\
\hline 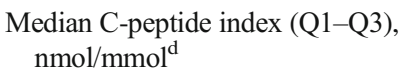 & $\begin{array}{l}0.34 \\
\quad(0.21-0.53)\end{array}$ & $\begin{array}{l}0.53 \\
\quad(0.35-0.78)\end{array}$ & $<0.001$ & $<0.001$ \\
\hline $\begin{array}{l}\text { Median AUC C-peptide/AUC } \\
\quad \text { glucose (Q1-Q3), nmol/mmol }\end{array}$ & $\begin{array}{l}0.25 \\
\quad(0.17-0.34)\end{array}$ & $\begin{array}{l}0.28 \\
\quad(0.21-0.36)\end{array}$ & $<0.001$ & $<0.001$ \\
\hline
\end{tabular}

Data are mean \pm SD unless otherwise stated

${ }^{a}$ Student's $t$ test was used to compare the means between groups

${ }^{\mathrm{b}}$ Multiple linear regression: adjusted for age, sex, BMI $z$ score and number of autoantibodies (if multiple autoantibodies)

${ }^{\mathrm{c}}$ Calculated with the trapezoidal rule. The average value of AUCs (/120 min) was presented for AUC glucose and AUC C-peptide

${ }^{\mathrm{d}}$ For ratios (C-peptide index, AUC C-peptide/AUC glucose), the values were log transformed for comparisons; $\mathrm{Q}$, quartile comparisons remained significant after adjustments were made for age, sex, BMI $z$ score and number of autoantibodies ( $p<0.001$ for all) (Table 4). However, none of the C-peptide measures showed a consistent trend across the monophasic subgroups except for the decline in the AUC C-peptide/ AUC glucose ratio.

\section{Discussion}

Our findings showed that among antibody-positive relatives of individuals with type 1 diabetes, the majority had a monophasic glucose-response pattern during a 2 h OGTT, and that pattern was associated with greater risk for developing type 1 diabetes. Moreover, among the monophasic group, those with a peak glucose at $30 \mathrm{~min}$ were at lower risk than those with peaks at either 60 or $90 \mathrm{~min}$. The differences in risk between the monophasic and biphasic groups and among the monophasic subgroups persisted after adjusting for baseline variables. The findings also showed that in comparison to the monophasic group, the biphasic group had higher early Cpeptide responses.

A strength of the study was the large number of participants, which allowed for subclassifications of the biphasic and monophasic groups. The analyses of these subgroups showed heterogeneity among the monophasic group for risk and Cpeptide response patterns, and among the biphasic group for timing of the $\mathrm{C}$-peptide response. In addition, we showed that the early $\mathrm{C}$-peptide response contributes significantly to the shape of the glucose-response curve.

There were some limitations. A longer OGTT with more frequent sampling than every $30 \mathrm{~min}$ could have resulted in a better understanding of the glucose curve shapes. Also, other factors, such as the effect of incretin hormones [18] or delayed gastric emptying on the shape of the glucose curve, were not assessed. In addition, approximately $26 \%$ with a non-diabetic OGTT at baseline did not meet the definition of a monophasic or a biphasic OGTT curve, which limits the generalisability of our results.

Findings from several studies suggest that the shape of the glucose-response curve is also an indicator of type 2 diabetes risk. Cross-sectional and longitudinal studies in adolescents and adults have shown that the form of the glucose-response curve is related to risk factors for type 2 diabetes and its development [5-12]. In one study [5] of non-diabetic white adults, a biphasic response during a $2 \mathrm{~h}$ OGTT was associated with lower BMI, better glucose tolerance, greater insulin sensitivity and greater beta cell function. Other studies in children and adolescents [10-12], and in adults [6-9], have confirmed this. No prior studies have examined the risk of type 1 diabetes in relation to shapes of glucose curves, nor the contribution of C-peptide responses to shapes of glucose-response curves in autoantibody-positive individuals.

To our knowledge, the risk of type 1 diabetes has not been compared among monophasic subgroups. Our finding of an association between the risk of type 1 diabetes and the timing of the peak glucose among the monophasic group is consistent with prior findings of an association of risk of type 2 diabetes with the timing of the peak glucose $[19,20]$. Those prior studies were not limited to the monophasic glucose pattern, however. The type 1 diabetes risk differences that we observed among the monophasic subgroups indicate that the monophasic glucose patterns should not be considered a uniform entity.

The greater risk of type 1 diabetes in the monophasic group could be explained by a lower early C-peptide response, 
Table 3 Metabolic characteristics of participants with a biphasic glucose pattern according to timing of second glucose peak during the baseline OGTT

\begin{tabular}{|c|c|c|c|c|}
\hline Characteristic & $\begin{array}{l}\text { Biphasic90 } \\
(n=346)\end{array}$ & $\begin{array}{l}\text { Biphasic120 } \\
(n=549)\end{array}$ & $p$ value $^{\mathrm{a}}$ & Adjusted $p$ value ${ }^{\mathrm{b}}$ \\
\hline AUC glucose, $\mathrm{mmol} / \mathrm{l}^{\mathrm{c}}$ & $6.81 \pm 1.15$ & $6.40 \pm 0.96$ & $<0.001$ & $<0.001$ \\
\hline AUC C-peptide, $\mathrm{nmol} / \mathrm{l}^{\mathrm{c}}$ & $1.94 \pm 0.81$ & $1.92 \pm 0.81$ & 0.783 & 0.558 \\
\hline 2 h C-peptide, nmol/1 & $1.84 \pm 0.90$ & $2.05 \pm 0.99$ & $<0.001$ & 0.001 \\
\hline Early C-peptide response, nmol/l & $1.64 \pm 0.85$ & $1.62 \pm 0.79$ & 0.810 & 0.828 \\
\hline $\begin{array}{l}\text { Median C-peptide index } \\
\quad(\mathrm{Q} 1-\mathrm{Q} 3), \mathrm{nmol}^{\mathrm{mmmol}} \mathrm{m}^{\mathrm{d}}\end{array}$ & $0.53(0.35-0.81)$ & $0.53(0.35-0.76)$ & 0.728 & 0.780 \\
\hline 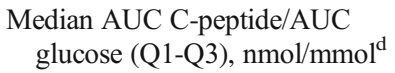 & $0.28(0.20-0.36)$ & $0.29(0.22-0.37)$ & 0.076 & 0.145 \\
\hline
\end{tabular}

Data are mean $\pm \mathrm{SD}$ unless otherwise stated

${ }^{a}$ Student's $t$ test was used to compare the means between groups

${ }^{\mathrm{b}}$ Multiple linear regression: adjusted for age, sex, BMI $z$ score and number of autoantibodies (if multiple autoantibodies)

${ }^{\mathrm{c}}$ Calculated with the trapezoidal rule. The average value of AUCs (/120 min) was presented for AUC glucose and AUC C-peptide

${ }^{\mathrm{d}}$ For ratios (C-peptide index, AUC C-peptide/AUC glucose), the values were log transformed for comparisons; $\mathrm{Q}$, quartile

which has been shown to decline with progression to type 1 diabetes $[15,16]$. Among those analysed, there was a lower early C-peptide response at baseline in those who developed type 1 diabetes later (ESM Table 3 ). A lower early C-peptide response could also possibly explain the greater risk in the monophasic90 subgroup than in the monophasic30 subgroup. However, trends in C-peptide measures were generally inconsistent across the monophasic subgroups.

The differences in the shapes of the glucose curves appear to be influenced by $\mathrm{C}$-peptide responses. Approximately one-third of the cohort had a biphasic OGTT with an overall lower glucose response; this was associated with a higher early C-peptide response. In addition, among the biphasic subgroups, whereas the biphasic90 subgroup had a decline in C-peptide between 30 and $60 \mathrm{~min}$, the biphasic120 subgroup had an increase in the C-peptide response during the same interval (Fig. $3 d)$. This could explain the earlier second rise in glucose in the biphasic 90 group than in the biphasic 120 group. It remains unclear though why there was a second increase in the glucose concentrations in the biphasic subgroups. Further studies that could assess the effect of incretin hormones, gastric emptying and absorption on the shape of the curve should be considered.
Table 4 Metabolic characteristics of participants with a monophasic glucose pattern according to timing of glucose peak during the baseline OGTT

\begin{tabular}{|c|c|c|c|c|c|}
\hline Characteristic & $\begin{array}{l}\text { Monophasic } 30 \\
(n=565)\end{array}$ & $\begin{array}{l}\text { Monophasic } 60 \\
(n=880)\end{array}$ & $\begin{array}{l}\text { Monophasic90 } \\
(n=287)\end{array}$ & $\begin{array}{l}p \\
\text { value }^{\mathrm{a}}\end{array}$ & $\begin{array}{l}\text { Adjusted } \\
p \text { value }\end{array}$ \\
\hline AUC glucose, $\mathrm{mmol} / \mathrm{l}^{\mathrm{c}}$ & $7.19 \pm 1.12$ & $8.08 \pm 1.34$ & $8.36 \pm 1.41$ & $<0.001$ & $<0.001$ \\
\hline AUC C-peptide, nmol// ${ }^{\mathrm{c}}$ & $2.09 \pm 0.87$ & $2.33 \pm 1.21$ & $1.89 \pm 1.13$ & 0.004 & $<0.001$ \\
\hline 2 h C-peptide, nmol/1 & $1.89 \pm 0.90$ & $1.06 \pm 0.69$ & $2.44 \pm 1.45$ & $<0.001$ & $<0.001$ \\
\hline $\begin{array}{l}\text { Early C-peptide } \\
\text { response, nmol/1 }\end{array}$ & $1.54 \pm 0.77$ & $2.04 \pm 1.02$ & $0.91 \pm 0.68$ & $<0.001$ & $<0.001$ \\
\hline $\begin{array}{l}\text { Median C-peptide index } \\
\quad(\mathrm{Q} 1-\mathrm{Q} 3), \mathrm{nmol} / \mathrm{mmol}^{\mathrm{d}}\end{array}$ & $\begin{array}{l}0.41 \\
\quad(0.27-0.59)\end{array}$ & $\begin{array}{l}0.29 \\
\quad(0.19-0.48)\end{array}$ & $\begin{array}{l}0.30 \\
\quad(0.16-0.52)\end{array}$ & $<0.001$ & $<0.001$ \\
\hline $\begin{array}{l}\text { Median AUC } \\
\text { C-peptide/AUC glucose } \\
\text { (Q1-Q3), nmol/mmol }{ }^{\mathrm{d}}\end{array}$ & $\begin{array}{l}0.28 \\
\quad(0.21-0.36)\end{array}$ & $\begin{array}{l}0.23 \\
\quad(0.16-0.32)\end{array}$ & $\begin{array}{l}0.20 \\
\quad(0.13-0.31)\end{array}$ & $<0.001$ & $<0.001$ \\
\hline
\end{tabular}

Data are mean \pm SD unless otherwise stated

${ }^{\text {a }}$ Student's $t$ test was used to compare the means between monophasic30 and monophasic 90

${ }^{\mathrm{b}}$ Multiple linear regression to compare monophasic30 and monophasic90: adjusted for age, sex, BMI $z$ score and number of autoantibodies (if multiple autoantibodies)

${ }^{\mathrm{c}}$ Calculated with the trapezoidal rule. The average value of AUCs (/120 min) was presented for AUC glucose and AUC C-peptide

${ }^{\mathrm{d}}$ For ratios (C-peptide index, AUC C-peptide/AUC glucose), the values were log transformed for comparisons; $\mathrm{Q}$, quartile 
The findings have implications for our understanding of the natural history of type 1 diabetes. The associations of glucose curve shapes with C-peptide measures suggest that changes in curve shape could be indicative of progression to type 1 diabetes. A better understanding of changes in shapes of OGTT curves could potentially improve the prediction of type 1 diabetes.

There are several additional unanswered questions that suggest future research. Among individuals with normal glucose tolerance, a monophasic pattern predominates [2-4], yet paradoxically, among autoantibody-positive individuals, the monophasic group had the highest risk for developing type 1 diabetes. We could not explain the inconsistency between the trend of increasing risk for the monophasic glucose peaks from 30 to $90 \mathrm{~min}$ and the lack of a clear trend for C-peptide responses. Finally, it would be of interest to determine whether the shape of the glucose curve changes over time during the course of progression to type 1 diabetes development.

Conclusions In conclusion, the present study is the first to show that shapes of plasma glucose curves during a $2 \mathrm{~h}$ OGTT are predictive of the risk of progression to type 1 diabetes among antibody-positive individuals. Furthermore, it shows that differences in glucose patterns appear to be explained, at least in part, by differences in C-peptide secretion patterns, particularly the magnitude and duration of the early C-peptide response to the oral glucose load.

Acknowledgements Members of the Type 1 Diabetes TrialNet Study Group and TrialNet Affiliate Centers are listed in the ESM.

Data availability The data were analysed or generated during the study and are available on request from the authors.

Funding The sponsor of the trial was the Type 1 Diabetes TrialNet Pathway to Prevention Study Group. The Type 1 Diabetes TrialNet Pathway to Prevention Study Group is a clinical trials network funded by the National Institutes of Health (NIH) through the National Institute of Diabetes and Digestive and Kidney Diseases, the National Institute of Allergy and Infectious Diseases and the Eunice Kennedy Shriver National Institute of Child Health and Human Development, through the cooperative agreements U01 DK061010, U01 DK061034, U01 DK061042, U01 DK061058, U01 DK085465, U01 DK085453, U01 DK085461, U01 DK085463, U01 DK085466, U01 DK085499, U01 DK085504, U01 DK085505, U01 DK085509, U01 DK103180, U01 DK103153, U01 DK085476, U01 DK103266 and the JDRF. The contents of this article are solely the responsibility of the authors and do not necessarily represent the official views of the NIH or the JDRF.

Duality of interest The authors declare that there is no duality of interest associated with this manuscript.
Contribution statement HMI, PX and JMS conceptualised the analysis, analysed and interpreted the data and wrote the manuscript. IML, DJB, JBM, JSS and JPP contributed to the design, interpreted the data and reviewed/edited the manuscript. HMI is the guarantor of this work, and all authors provided final approval of the manuscript prior to publishing.

\section{References}

1. Expert Committee on the Diagnosis and Classification of Diabetes Mellitus (2003) Report of the Expert Committee on the diagnosis and classification of diabetes mellitus. Diabetes Care 26:S5-S20

2. Zhao X, Peter A, Fritsche J et al (2009) Changes of the plasma metabolome during an oral glucose tolerance test: is there more than glucose to look at? Am J Physiol Endocrinol Metab 296: E384-E393

3. Knopf CF, Cresto JC, Dujovne IL, Ramos O, de Majo SF (1977) Oral glucose tolerance test in 100 normal children. Acta Diabetol Lat 14:95-103

4. Chandalia HB, Boshell BR (1970) Diagnosis of diabetes. The size and nature of carbohydrate load. Diabetes 19:863-869

5. Tschritter O, Fritsche A, Shirkavand F, Machicao F, Häring H, Stumvoll M (2003) Assessing the Shape of the Glucose Curve During an Oral Glucose Tolerance Test. Diabetes Care 26:10261033

6. Kanauchi M, Kimura K, Kanauchi K, Saito Y (2005) Beta-cell function and insulin sensitivity contribute to the shape of plasma glucose curve during an oral glucose tolerance test in non-diabetic individuals. Int J Clin Pract 59:427-432

7. Trujillo-Arriaga HM, Román-Ramos R (2008) Fitting and evaluating the glucose curve during a quasi continuous sampled oral glucose tolerance test. Comput Biol Med 38:185-195

8. Abdul-Ghani MA, Lyssenko V, Tuomi T, DeFronzo RA, Groop L (2010) The shape of plasma glucose concentration curve during OGTT predicts future risk of type 2 diabetes. Diabetes Metab Res Rev 26:280-286

9. Tura A, Morbiducci U, Sbrignadello S, Winhofer Y, Pacini G, Kautzky-Willer A (2011) Shape of glucose, insulin, C-peptide curves during a 3-h oral glucose tolerance test: any relationship with the degree of glucose tolerance? Am J Physiol Regul Integr Comp Physiol 300:R941-R948

10. Kim JY, Coletta DK, Mandarino LJ, Shaibi GQ (2012) Glucose response curve and type 2 diabetes risk in Latino adolescents. Diabetes Care 35:1925-1930

11. Bervoets L, Mewis A, Massa G (2015) The shape of the plasma glucose curve during an oral glucose tolerance test as an indicator of beta cell function and insulin sensitivity in end-pubertal obese girls. Horm Metab Res 47:445-451

12. Nolfe G, Spreghini MR, Sforza RW, Morino G, Manco M (2012) Beyond the morphology of the glucose curve following an oral glucose tolerance test in obese youth. Eur J Endocrinol 166:107114

13. Mahon JL, Sosenko JM, Rafkin-Mervis L et al (2009) The TrialNet natural history study of the development of type 1 diabetes: objectives, design, and initial results. Pediatr Diabetes 10:97-104

14. Clinical Trials.gov archives (2012) Available from https:// clinicaltrials.gov/archive/NCT00097292/2012_02_10/changes. Accessed 25 July 2017

15. Sosenko JM, Palmer JP, Rafkin LE et al (2010) Trends of earlier and later responses of C-peptide to oral glucose challenges with 
progression to type 1 diabetes in diabetes prevention trial-type 1 participants. Diabetes Care 33:620-625

16. Sosenko JM, Skyler JS, Herold KC, Palmer JP, Type 1 Diabetes TrialNet and Diabetes Prevention Trial-Type 1 Study Groups (2012) The metabolic progression to type 1 diabetes as indicated by serial oral glucose tolerance testing in the Diabetes Prevention Trial-type 1. Diabetes 61:1331-1337

17. Tura A, Kautzky-Willer A, Pacini G (2006) Insulinogenic indices from insulin and C-peptide: comparison of beta-cell function from OGTT and IVGTT. Diabetes Res Clin Pract 72:298-301
18. Creutzfeldt W, Nauck M (1992) Gut hormones and diabetes mellitus. Diabetes Metab Rev 8:149-177

19. Abdul-Ghani MA, Stern MP, Lyssenko V, Tuomi T, Groop L, Defronzo RA (2010) Minimal contribution of fasting hyperglycemia to the incidence of type 2 diabetes in subjects with normal 2-h plasma glucose. Diabetes Care 33:557-561

20. Zhou W, Gu Y, Li H, Luo M (2006) Assessing 1-h plasma glucose and shape of the glucose curve during oral glucose tolerance test. Eur J Endocrinol Eur Fed Endocr Soc 155:191-197 